\title{
Nitrooleic Acid Protects against Cisplatin Nephropathy: Role of COX-2/mPGES-1/PGE 2 Cascade
}

\author{
Haiping Wang, ${ }^{1}$ Zhanjun Jia, ${ }^{2}$ Jing Sun, ${ }^{1}$ Liang Xu, ${ }^{1}$ Bing Zhao, ${ }^{1}$ Kezhou Yu, \\ Meng Yang, ${ }^{1}$ Tianxin Yang, ${ }^{2}$ and Rong Wang ${ }^{1}$ \\ ${ }^{1}$ Department of Nephrology, Provincial Hospital Affiliated to Shandong University, No. 324 Jingwu Road, Jinan, \\ Shandong 250013, China \\ ${ }^{2}$ Department of Internal Medicine, University of Utah and Salt Lake Veterans Affairs Medical Center, Salt Lake City, \\ UT 84112, USA
}

Correspondence should be addressed to Tianxin Yang; tianxin.yang@hsc.utah.edu and Rong Wang; cktwhpvvv@163.com

Received 19 September 2014; Revised 16 January 2015; Accepted 21 January 2015

Academic Editor: Alex Kleinjan

Copyright (C) 2015 Haiping Wang et al. This is an open access article distributed under the Creative Commons Attribution License, which permits unrestricted use, distribution, and reproduction in any medium, provided the original work is properly cited.

\begin{abstract}
Nitrooleic acid $\left(\mathrm{OA}-\mathrm{NO}_{2}\right)$ is an endogenous lipid product which has novel signaling properties, particularly the activation of peroxisome proliferator-activated receptors. The current study aimed to evaluate the protective effects of $\mathrm{OA}-\mathrm{NO}_{2}$ against cisplatininduced kidney injury in mice. Mice were pretreated with $\mathrm{OA}-\mathrm{NO}_{2}$ for $48 \mathrm{~h}$ before cisplatin administration, and the cisplatin-caused nephrotoxicity was evaluated. After the cisplatin treatment $(72 \mathrm{~h})$, the vehicle-treated mice displayed renal dysfunction, as evidenced by the elevated plasma urea and creatinine, which was consistent with the histological damage, such as tubular necrosis, dilation, protein cast, and desquamation of epithelial cells. In contrast, the severity of the renal dysfunction and histological change were reduced in the $\mathrm{OA}-\mathrm{NO}_{2}$ pretreated mice. The renal COX-2 and mPGES-1 mRNAs and their respective proteins expression, together with the renal $\mathrm{PGE}_{2}$ amounts, were induced by the cisplatin treatment, but their initiation was reduced by $\mathrm{OA}-\mathrm{NO}_{2}$. Moreover, the circulating TNF- $\alpha$, renal TNF- $\alpha$, IL-1 $\beta$, MCP-1, ICAM-1, and VACAM-1 mRNA levels were higher in the cisplatin-treated mice, compared with the controls, but they were attenuated in the $\mathrm{OA}-\mathrm{NO}_{2}$ pretreatment group. In summary, the pretreatment with $\mathrm{OA}$ $\mathrm{NO}_{2}$ remarkably ameliorated the cisplatin-induced kidney injury in mice, possibly via the inhibition of the inflammatory response, associated with the COX-2/mPGES-1/PGE 2 cascade.
\end{abstract}

\section{Introduction}

cis-Diamminedichloroplatinum (cisplatin) is a highly effective antineoplastic DNA-alkylating agent, and the cisplatinbased combination chemotherapy regimens are currently used as the front-line therapy in the treatment of a number of cancer types: testicular cancer, cancer of the bladder, epithelial ovarian cancer, endometrial cancer, cancer of the head and neck, ovarian germ cell tumors, advanced cervical cancer, mesothelioma, non-small-cell lung cancer [1], and so forth. The therapeutic effects of cisplatin are significantly improved by its dose elevation. However, the high-dose therapy with cisplatin is limited by the emergence of serious adverse effects, particularly nephrotoxicity [2], which is a frequent adverse result with about $25-35 \%$ patients suffering a decline in their renal functions after a single dose of cisplatin [3].

The severity of toxicity in the early clinical trials called into question the use of cisplatin as a chemotherapy agent. Hydration protocols were developed that reduced the nephrotoxicity and allowed an increase of the dose to achieve therapeutic levels [4]. However, even with vigilant hydration, approximately one-third of the patients treated with cisplatin have a transient elevation of blood urea nitrogen levels or other evidence of kidney damage in the days following the cisplatin treatment [5].

Multiple studies have examined the mechanisms of cisplatin-induced kidney injury. The signaling mechanisms, responsible for the cisplatin-induced cytotoxicity, appear to 
be multifactorial, involving inflammation, oxidative stress, and caspase actions [6]. Indeed, growing evidence suggests that the inhibition of inflammatory gene expression is partially capable of attenuating cisplatin-induced renal injury [7]. However, with the exception of hydration with saline, no specific treatments have been performed against cisplatininduced nephrotoxicity [4]. Therefore, an urgent need exists to develop new, effective treatments against cisplatin-induced kidney injury.

Nitrated free fatty acids $\left(\mathrm{NO}_{2}-\mathrm{FA}\right)$, particularly the nitroalkene derivatives of linoleic acid (nitrolinoleic acid; $\left.\mathrm{LNO}_{2}\right)$ and nitrooleic acid $\left(\mathrm{OA}-\mathrm{NO}_{2}\right)$, are identified as endogenous molecules with several attractive signaling properties [8, 9]. Nitrooleic acid $\left(\mathrm{OA}-\mathrm{NO}_{2}\right)$ and related nitroalkenes are present in normal tissues at nM concentrations and can increase during inflammation to almost $\mu \mathrm{M}$ concentrations, indicating fatty acid nitroalkenes could induce a variety of pharmacological effects [10]. An increasing body of findings attests that nitrated free fatty acid exerts potent anti-inflammatory actions in vitro and in vivo. Diverse signaling properties have been attributed to nitrooleic acid. In animal models, $\mathrm{OA}-\mathrm{NO}_{2}$ has demonstrated benefits in hypertension [11], vascular neointimal proliferation [12], obesity with the metabolic syndrome [13], and hyperglycemia in diabetes [14]. Considerable evidence demonstrates that OA$\mathrm{NO}_{2}$ exerts potent anti-inflammatory actions. The pretreatment with $\mathrm{OA}-\mathrm{NO}_{2}$ inhibits the lipopolysaccharide- (LPS-) induced $\mathrm{NF}-\kappa \mathrm{B}$ activation both in vivo and in isolated macrophages [15]. Moreover, $\mathrm{OA}-\mathrm{NO}_{2}$ attenuated colonic inflammation and improved the clinical symptoms in experimental inflammatory bowel disease, dependent on the PPAR gamma pathway in mice [16]. We previously demonstrated that nitrooleic acid exhibited protective effects against the renal injury in an ischemia and reperfusion mouse model and a LPS-induced endotoxic model via anti-inflammation and antioxidative stress $[17,18]$. The present study seeks to examine the potential therapeutic effects of $\mathrm{OA}-\mathrm{NO}_{2}$ in cisplatin-caused nephropathy.

\section{Materials and Methods}

2.1. Materials. Cisplatin (cis-diamminedichloroplatinum (II)) was purchased from Sigma-Aldrich (St. Louis, MO, USA). The TO901317 compound was purchased from the Cayman Chemical Company (Ann Arbor, MI, USA) and dissolved in DMSO. The two regioisomers of $\mathrm{OA}-\mathrm{NO}_{2}, 9$ - and 10 -nitrooleic acids, are formed in vivo in approximately equal proportions by nitration of oleic acid [19]. Both compounds were purchased from Cayman Chemical (Ann Arbor, MI, USA), dissolved in dimethyl sulfoxide (DMSO), and used as a $1: 1$ mixture of the isomers.

2.2. Animal Experiments. Male C57BL/6 mice (8-10-weekold) were maintained on a standard rodent chow with free access to water. The animals were divided into three groups: control (control; $n=6$ ), cisplatin-induced kidney injury (cisplatin; $n=12$ ), and cisplatin-induced kidney injury with OA$\mathrm{NO}_{2}$ treatment (cisplatin $+\mathrm{OA}-\mathrm{NO}_{2} ; n=13$ ) groups. Cisplatin was dissolved in saline at a concentration of $2 \mathrm{mg} / \mathrm{mL}$ and used to treat the mice by a single intraperitoneal (i.p.) injection $(20 \mathrm{mg} / \mathrm{Kg})$, in both the cisplatin and cisplatin + $\mathrm{OA}-\mathrm{NO}_{2}$ groups. The OA- $\mathrm{NO}_{2}$ was dissolved in $100 \%$ DMSO at $100 \mathrm{mg} / \mathrm{mL}$. The mice were pretreated for $48 \mathrm{~h}$ with DMSO $($ cisplatin + vehicle $)$ or $\mathrm{OA}-\mathrm{NO}_{2}\left(\right.$ cisplatin $\left.+\mathrm{OA}-\mathrm{NO}_{2}\right)$ at a dose of $2 \mathrm{mg} / \mathrm{kg} / \mathrm{d}$ via a microosmotic pump (DURECT Corporation, Cupertino, CA, USA). The control mice group received an i.p. injection of saline. After mouse euthanasia (72 $\mathrm{h}$ after the cisplatin treatment), blood samples were obtained from the inferior vena cava, and both kidneys were excised. All protocols employing mice were conducted in accordance with the principles and guidance of the Ethics Committee of Shandong University.

2.3. Renal Function. Plasma urea (BUN) and creatinine (CREA) levels were determined to assess the renal function. After blood collection, the serum levels of these toxicity markers were measured immediately by using a blood chemistry analyzer.

2.4. Renal Histology. Mice kidneys were fixed in $4 \%$ paraformaldehyde, embedded in paraffin, sectioned at $4 \mu \mathrm{m}$, and stained with hematoxylin and eosin ( $\mathrm{HE})$ and periodic acid-Schiff (PAS), respectively, by standard methods. The tissue damage was indicated by tubular lysis, dilation, necrosis, and cast formation and glomeruli congestion and atrophy. And the scoring scale scores (none (-); mild damage $(+)$; moderate damage $(++)$; and severe damage $(+++))$ are semiquantitative scores given by a pathologist unaware of the type of treatment.

2.5. Real-Time RT-PCR. Kidneys were harvested and preserved in the RNAlater solution (Sangong Biotech, China) at $-20^{\circ} \mathrm{C}$ until RNA extraction. The total RNA was isolated by the use of TRIzol (Invitrogen, CA, USA), and cDNA was synthesized through Superscript (TaKaRa, Japan). Real-time RT-PCR was carried out employing a QuantiTect SYBR Green kit (Qiagen, Germany) on an ABI Prism 7500 realtime PCR (RT-PCR) instrument, equipped with the appropriate software (Applied Biosystems, CA, USA). The oligonucleotide sequences (Sangong Biotech, Shanghai, China) used for the real-time PCR were as follows: GAPDH, sense $5^{\prime}$-GTCTTCACTACCATGGAGAGG-3' and antisense $5^{\prime}$-TCATGGATGACCTTGGCCAG-3'; TNF- $\alpha$, sense $5^{\prime}$-TCCCCAAAGGGATGAGAAG- $3^{\prime}$ and antisense $5^{\prime}$ CACTTGGTGGTTTGCTACGA-3'; IL-1 $\beta$, sense $5^{\prime}$-ACTGTGAAATGCCACCTTTTG- $3^{\prime}$ and antisense $5^{\prime}$-TGTTGATGTGCTGCTGTGAG-3'; COX-2, sense $5^{\prime}$-AGGACTCTGCTCACGAAGGA-3 $3^{\prime}$ and antisense $5^{\prime}$-TGACATGGATTGGAACAGCA-3 ${ }^{\prime}$; MCP-1, sense $5^{\prime}$-GCTCTCTCTTCCTCCACCAC- $3^{\prime}$ and antisense $5^{\prime}$-ACAGCTTCTTTGGGACACCT-3'; ICAM-1, sense $5^{\prime}$-CGCTTCCGCTACCATCAC- $3^{\prime}$ and antisense GGCGGCTCAGTATCCTC- ${ }^{\prime}$; 


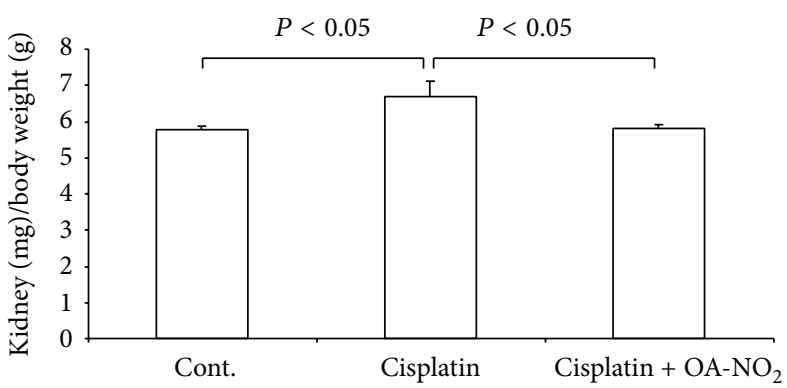

(a)

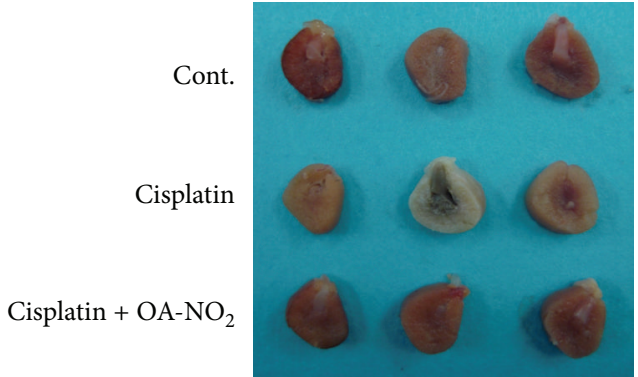

(b)

FIGURE 1: Pretreatment with $\mathrm{OA}-\mathrm{NO}_{2}$ attenuated the kidney swelling (a) and improved the kidney appearance (b). Cont.: $N=6$; cisplatin: $N=12$; cisplatin $+\mathrm{OA}-\mathrm{NO}_{2}: N=13$. Data are mean $\pm \mathrm{SE}$.

VCAM-1, sense $5^{\prime}$-GGAGAGACAAAGCAGAAGTGG-3' and antisense $5^{\prime}$-AACACAAGCGTGGATTTGG-3'.

2.6. Western Blotting. The total protein in the kidney tissue was extracted by a lysis buffer and the concentrations were determined through the Coomassie reagent. Equal amounts of the tissue protein $(50 \mu \mathrm{g})$ were denatured at $100^{\circ} \mathrm{C}$ for $10 \mathrm{~min}$, separated by SDS-PAGE, and transferred onto nitrocellulose membranes. The blots were blocked overnight with $5 \%$ nonfat dry milk in Tris-buffered saline (TBS), followed by incubation for $1 \mathrm{~h}$ with rabbit polyclonal antibody, raised against mouse COX-2 and mPGES-1 (Cayman Chemical, MI, USA). The blots were washed with TBS followed by incubation with a horseradish peroxidase-conjugated secondary antibody and the immune complexes were detected using the ECL system (Amersham). The Bio-Rad electrophoresis image analyzer (Bio-Rad, UK) was used to quantify the protein signals.

2.7. Measurement of Renal PGE $E_{2}$ Content. The whole kidneys were snap-frozen in liquid nitrogen immediately upon collection and stored at $-80^{\circ} \mathrm{C}$. Then, the kidney tissues were lysed and homogenized, as previously described [13], and the $\mathrm{PGE}_{2}$ contents were measured using a commercially available $\mathrm{PGE}_{2}$ kit (Boshide, Biotech, China), according to the manufacturer's instructions.

2.8. Statistical Analysis. The values shown represent means \pm $\mathrm{SE}$. The data were analyzed by one-way analysis of variance (ANOVA), followed by a Bonferroni posttest. A $P$ value $<0.05$ was considered statistically significant.

\section{Results}

3.1. $\mathrm{OA}-\mathrm{NO}_{2}$ Ameliorates Cisplatin-Induced Kidney Swelling. Following the cisplatin treatment, the mice kidneys became pale and ischemic, in contrast to the control mice kidneys, whereas the pretreatment with $\mathrm{OA}-\mathrm{NO}_{2}$ improved the kidney appearance (Figure 1(b)). The degree of kidney swelling secondary to the cisplatin-induced renal injury appeared more serious than that in the control mice group, while the pretreatment with $\mathrm{OA}-\mathrm{NO}_{2}$ ameliorated the kidney swelling, as confirmed by the different kidney wet weight (cisplatin: $6.68 \pm 0.42$ versus control: $5.78 \pm 0.11, P<0.05$; cisplatin: $6.68 \pm 0.42$ versus cisplatin $\left.+\mathrm{OA}-\mathrm{NO}_{2}: 5.81 \pm 0.08, P<0.05\right)$ (Figure 1(a)).

3.2. $\mathrm{OA}-\mathrm{NO}_{2}$ Ameliorates Cisplatin-Induced Renal Dysfunction. The renal function was assessed by the plasma BUN and creatinine levels. The cisplatin injection induced severe renal dysfunction, increasing plasma BUN from $23.3 \pm 1.35$ to $114.2 \pm 22.1 \mathrm{mg} / \mathrm{dL}(P<0.05)$ (Figure $2(\mathrm{a}))$ and plasma creatinine from $0.24 \pm 0.02$ to $0.93 \pm 0.25 \mathrm{mg} / \mathrm{dL}(P<0.05)$ (Figure 2(b)). Interestingly, the pretreatment with $\mathrm{OA}-\mathrm{NO}_{2}$ resulted in reduced plasma BUN $(46.7 \pm 4.82$ versus $114.2 \pm$ $22.1 \mathrm{mg} / \mathrm{dL}, P<0.05)$ (Figure $2(\mathrm{a}))$ and creatinine $(0.40 \pm 0.03$ versus $0.93 \pm 0.25 \mathrm{mg} / \mathrm{dL}, P<0.05)$ levels, compared with the cisplatin group (Figure 2(b)).

3.3. $\mathrm{OA}-\mathrm{NO}_{2}$ Attenuates Cisplatin-Induced Histological Changes in the Kidney. Following the cisplatin treatment, the mice in the cisplatin group displayed severe renal pathological changes, characterized by the distortion of the overall renal morphology, dilation of renal tubules, and appearance of protein cast, as well as severe tubular necrosis and interstitial inflammation. Moreover, the renal corpuscles displayed extensive congestion filling up the glomerular capillary loops, and some glomeruli were atrophied (Figures 3(a), 3(b), and 3(c)). Remarkably, these histological changes were alleviated after the pretreatment with $\mathrm{OA}-\mathrm{NO}_{2}$. Indeed, the mice in the $\mathrm{OA}-\mathrm{NO}_{2}$ pretreatment group exhibited considerably decreased semiquantitative histological damage scores, compared with those of the cisplatin group (Table 1).

3.4. Activation of Renal COX-2 by Cisplatin Treatment. To determine the induction of COX-2 in the cisplatin-induced renal lesions, we examined COX-2 mRNA and protein levels in the kidneys after the cisplatin administration. COX-2 mRNA levels escalated strikingly (6.0-fold) after the cisplatin treatment. The pretreatment with $\mathrm{OA}-\mathrm{NO}_{2}$ substantially reduced this increase (Figure 4). Similarly, western blotting showed that the COX-2 protein content was elevated 23.1-fold three days after the cisplatin treatment, and the pretreatment with $\mathrm{OA}-\mathrm{NO}_{2}$ diminished this induction (Figure 4). 


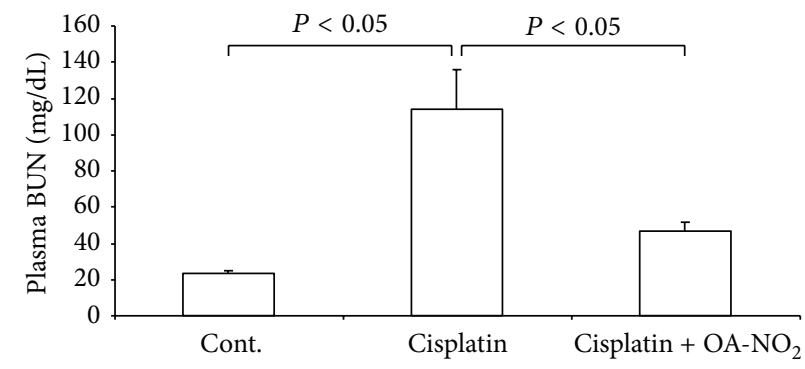

(a)

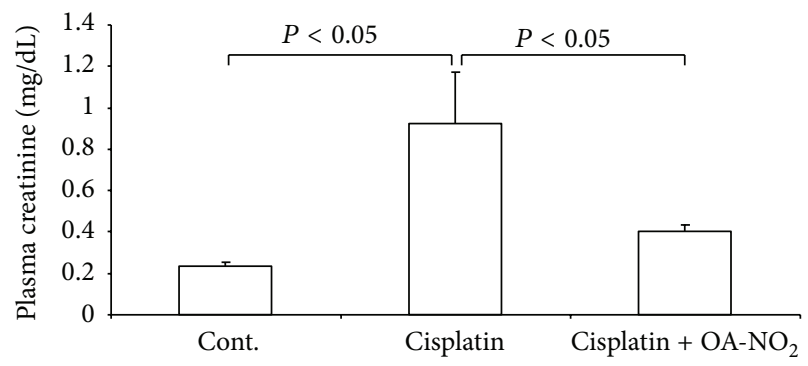

(b)

Figure 2: Plasma BUN (a) and creatinine (b) levels in control, cisplatin vehicle, and cisplatin $+\mathrm{OA}-\mathrm{NO}_{2}$ mice. Cont.: $N=6$; cisplatin: $N=12$; cisplatin $+\mathrm{OA}-\mathrm{NO}_{2}: \mathrm{N}=13$. Data are mean $\pm \mathrm{SE}$.
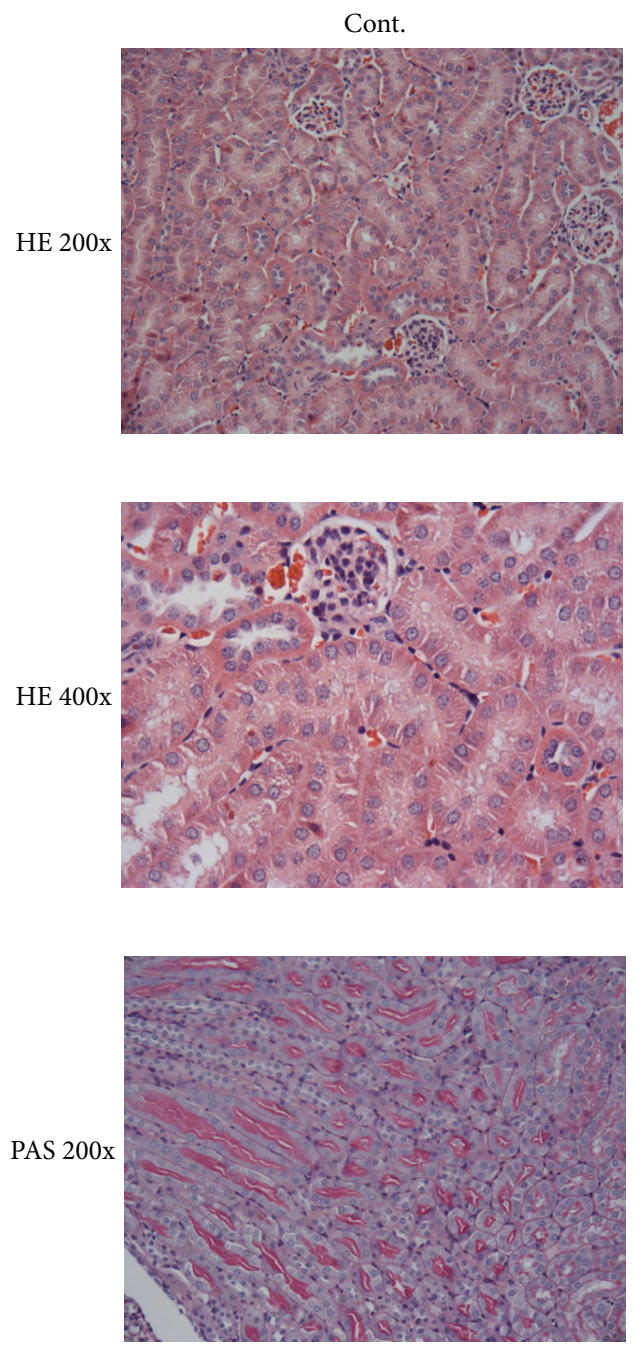

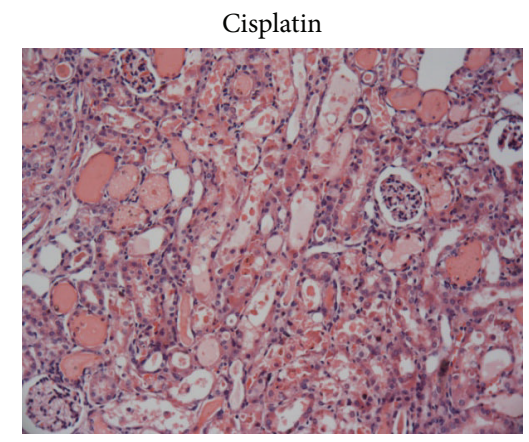

(a)

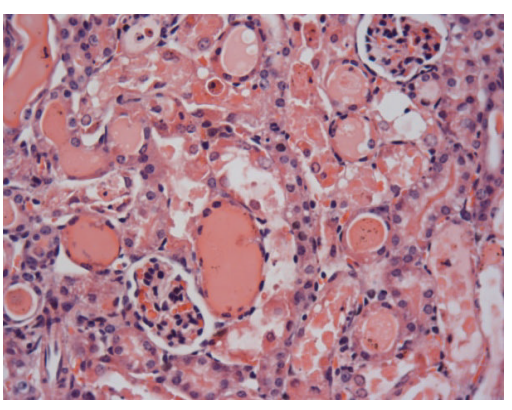

(b)
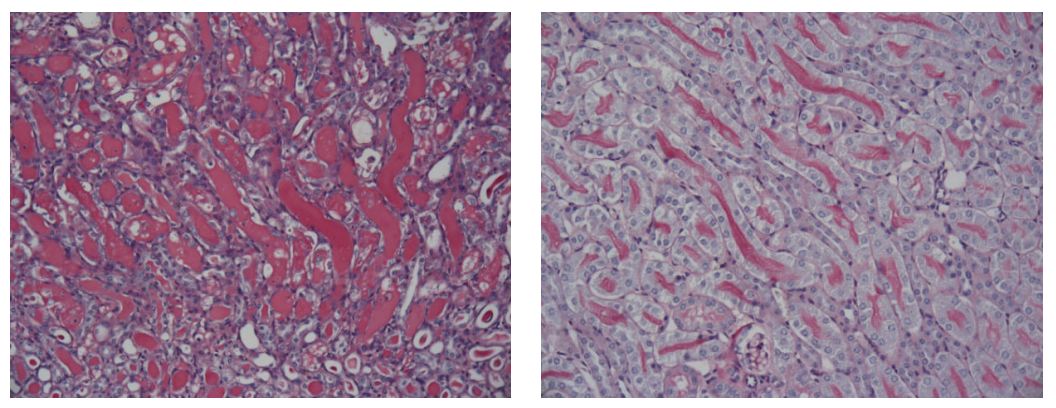

(c)

FIGURE 3: Morphological changes of cisplatin-induced renal injury in control, cisplatin vehicle, and cisplatin $+\mathrm{OA}^{-\mathrm{NO}_{2}}$ mice. ((a)-(c)) Representative photomicrographs with hematoxylin and eosin staining (magnification of 200 and 400) and periodic acid-Schiff staining (magnification 200) of renal cortex of kidneys; Cont.: $N=6$; cisplatin: $N=12$; cisplatin $+\mathrm{OA}_{-} \mathrm{NO}_{2}: N=13$. Data are mean $\pm \mathrm{SE}$. 


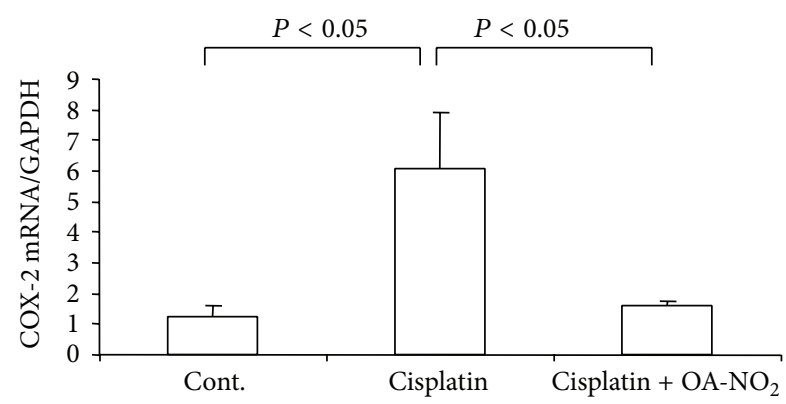

(a)

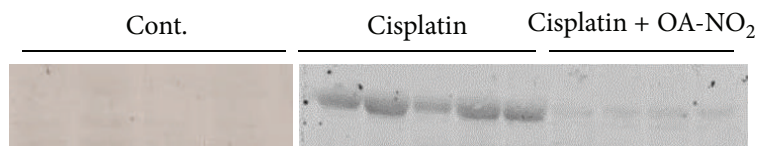

(b)

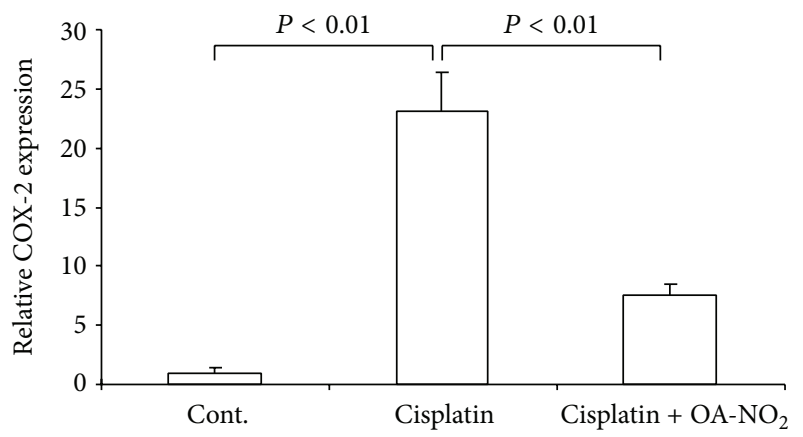

(c)

FIgURE 4: Renal COX-2 mRNA and protein expressions in control, cisplatin vehicle, and cisplatin $+\mathrm{OA}-\mathrm{NO}_{2}$ mice. (a) qRT-PCR analysis of renal COX-2 mRNA; (b) western blotting analysis of renal COX-2 protein expression; (c) densitometric value of COX2 protein; Cont.: $N=6$; cisplatin: $N=12$; cisplatin + OA- $\mathrm{NO}_{2}$ : $N=13$. Data are mean \pm SE.

TABLE 1: Morphological changes of cisplatin-induced renal injury in control, cisplatin vehicle, and cisplatin $+\mathrm{OA}-\mathrm{NO}_{2}$ mice as assessed by histological analysis.

\begin{tabular}{lccc}
\hline \multirow{2}{*}{ Changes } & \multicolumn{3}{c}{ Groups } \\
& Cont. & Cisplatin & Cisplatin $+\mathrm{OA}^{-\mathrm{NO}_{2}}$ \\
\hline Glomerular congestion & - & ++ & + \\
Glomerular atrophy & - & ++ & + \\
Cast & - & +++ & + \\
Tubular brush border loss & - & ++ & + \\
Tubular necrosis & - & ++ & + \\
Tubular atrophy & - & +++ & + \\
Interstitial inflammation & - & +++ & +
\end{tabular}

Scoring scalescores (none $(-)$; mild damage $(+)$; moderate damage $(++)$; and severe damage $(+++)$ ) are semiquantitative scores given by a pathologist unaware of the type of treatment.

3.5. Activation of Renal mPGES-1 and $P G E_{2}$ by Cisplatin Treatment. Next, we examined the mPGES-1 expression levels in the kidneys after the cisplatin administration. The mPGES1 protein level markedly rose 2.1-fold after the cisplatin treatment. The pretreatment with $\mathrm{OA}-\mathrm{NO}_{2}$ greatly lowered

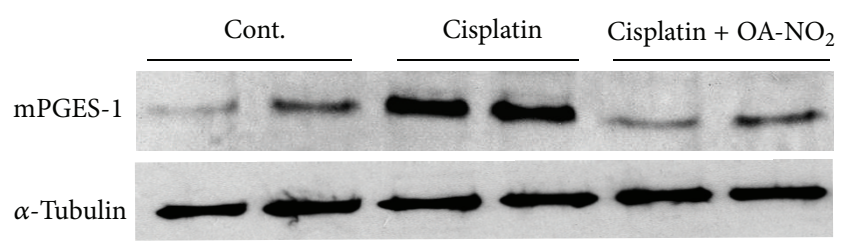

(a)

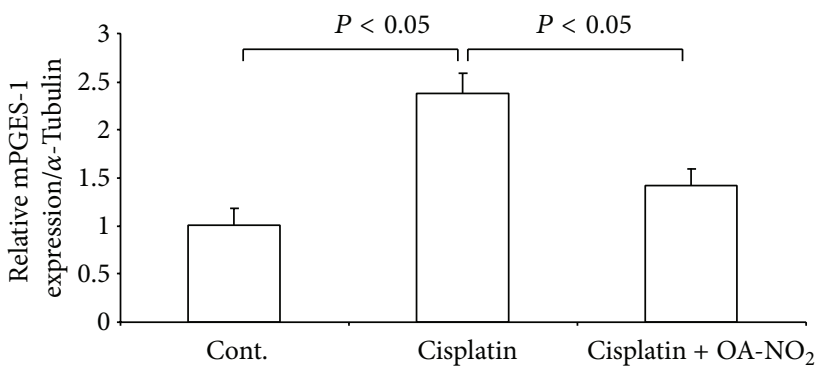

(b)

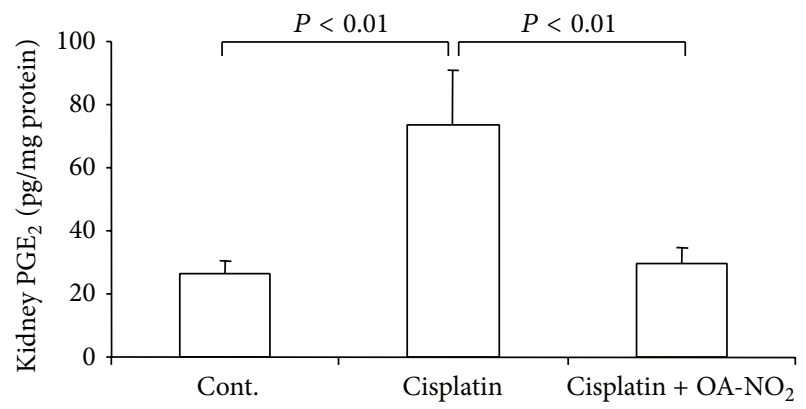

(c)

FIGURE 5: Renal mPGES-1 expression and renal PGE 2 content in control, cisplatin vehicle, and cisplatin $+\mathrm{OA}-\mathrm{NO}_{2}$ mice. (a) Immunoblot analysis of mPGES-1 expression; (b) densitometric value of mPGES-1 protein; (c) enzyme-linked immunosorbent assay analysis of renal PGE $\mathrm{PG}_{2}$ content. Cont.: $N=6$; cisplatin: $N=12$; cisplatin $+\mathrm{OA}-\mathrm{NO}_{2}: N=13$. Data are mean $\pm \mathrm{SE}$.

this increase (Figure 5(a)). To determine the COX-2/mPGES1 cascade, we measured the kidney $\mathrm{PGE}_{2}$ content via enzymelinked immunosorbent assay. At $72 \mathrm{~h}$ after the cisplatin treatment, the kidney $\mathrm{PGE}_{2}$ content was significantly enhanced in the cisplatin group mice. This augmentation was considerably blunted by the pretreatment with $\mathrm{OA}-\mathrm{NO}_{2}$ (Figure 5(c)).

\section{6. $\mathrm{OA}-\mathrm{NO}_{2}$ Attenuates Cisplatin-Induced Renal Expression} of Cytokines. TNF- $\alpha$ is a well-established pathogenic factor in the inflammatory responses in cisplatin-induced kidney injury. Therefore, the emphasis in our study was placed on the assessment of renal TNF- $\alpha$ mRNA and circulating TNF- $\alpha$ level. The renal TNF- $\alpha$ mRNA was increased 4.7fold in the cisplatin-treatment group compared with the control mice group, and the pretreatment with $\mathrm{OA}-\mathrm{NO}_{2}$ strikingly reduced the degree of TNF- $\alpha$ mRNA expressions (Figure 6(b)). Similarly, the circulating TNF- $\alpha$ level was elevated $(6.2$-fold) in the cisplatin-treated mice, while the elevation was attenuated by $50 \%$ after the pretreatment with $\mathrm{OA}-\mathrm{NO}_{2}$ (Figure 6(a)). The renal interleukin- (IL-) $1 \beta$ 


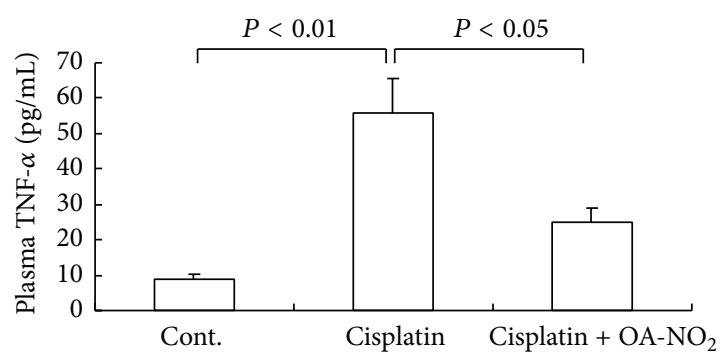

(a)

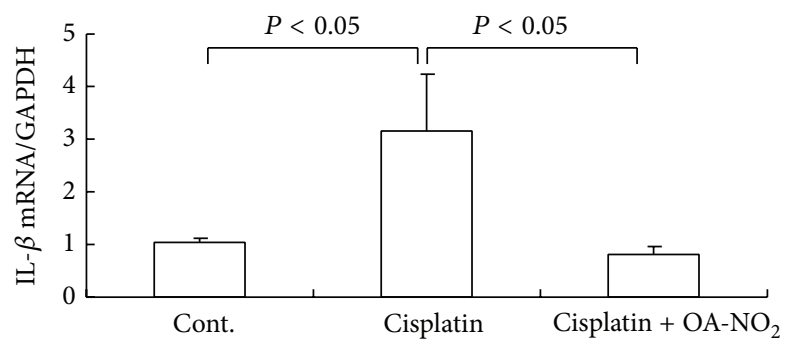

(c)

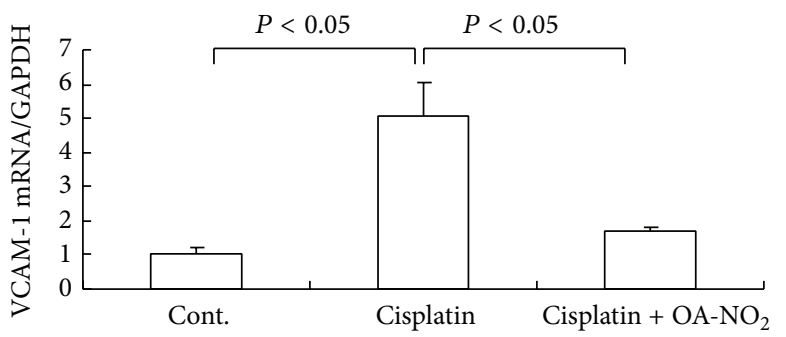

(e)

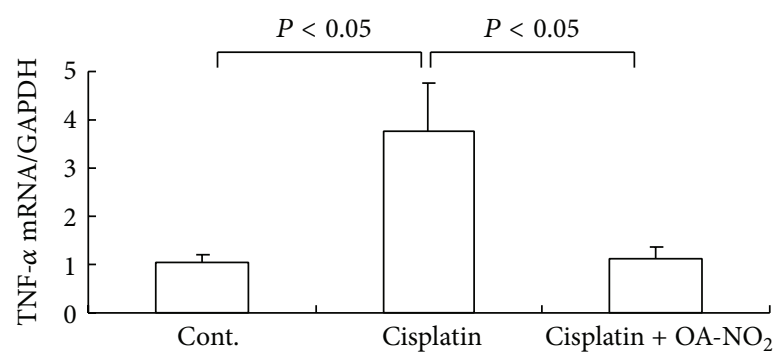

(b)

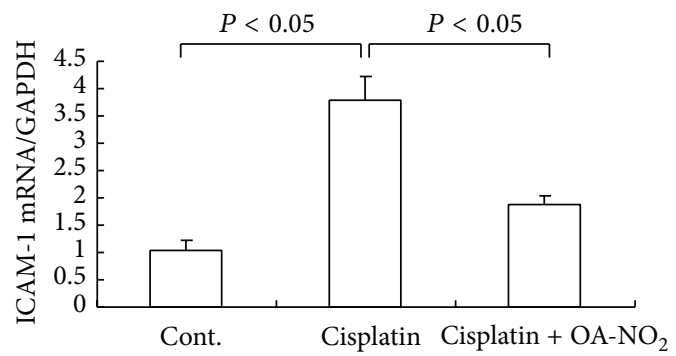

(d)

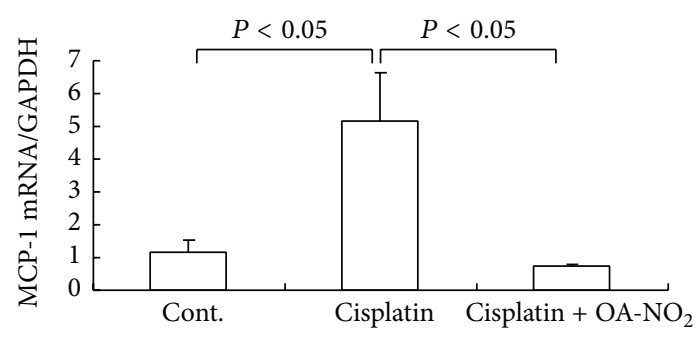

(f)

FIGURE 6: Renal proinflammatory cytokines and adhesion molecules in control, cisplatin vehicle, and cisplatin $+\mathrm{OA}-\mathrm{NO} \mathrm{O}_{2}$ mice. (a) Enzymelinked immunosorbent assay analysis of circulating TNF- $\alpha$; the real-time RT-PCR of renal TNF- $\alpha$ mRNA (b), renal IL- $1 \beta$ mRNA (c), renal ICAM-1 mRNA (d), renal VCAM-1 mRNA (e), and renal MCP-1 mRNA (f) expression. Cont.: $N$ = 6; cisplatin: $N=12$; cisplatin + OA-NO : $N=13$. Data are mean \pm SE.

mRNA expression exhibited similar patterns as renal TNF$\alpha$ (Figure 6(c)). Likewise, cisplatin induced the renal mRNA expression of chemokines and adhesion molecules, including the monocyte chemoattractant protein 1 (MCP-1), intercellular adhesion molecule-1 (ICAM-1), and vascular cell adhesion molecule-1 (VCAM-1); this effect was remarkably mitigated by the pretreatment with $\mathrm{OA}-\mathrm{NO}_{2}$ (Figures $6(\mathrm{~d})-$ $6(\mathrm{f}))$. Overall, the pretreatment with $\mathrm{OA}-\mathrm{NO}_{2}$ alleviated the expression of the proinflammatory cytokines, chemokines, and adhesion molecules in the cisplatin-induced kidney injury.

\section{Discussion}

Nitrooleic acid $\left(\mathrm{OA}-\mathrm{NO}_{2}\right)$ and its nitroalkene derivatives are robust endogenous ligands for the peroxisome proliferatoractivated receptor- $\gamma(\operatorname{PPAR} \gamma)$, although their increased concentrations activate also $\operatorname{PPAR} \alpha$ and $\operatorname{PPAR} \delta[20,21]$. To date, $\mathrm{OA}-\mathrm{NO}_{2}$ is established to have several properties, such as the therapeutic effects against dyslipidemia and hyperglycemia, associated with the metabolic syndrome. Moreover, the existing evidence indicates that $\mathrm{OA}-\mathrm{NO}_{2}$ exerts potent anti-inflammatory actions. In vitro, it was determined that $\mathrm{OA}-\mathrm{NO}_{2}$ inhibited the platelet aggregation, neutrophil activation, and nuclear factor $\kappa \mathrm{B}$-mediated cytokine release and stimulated the heme oxygenase- (HO-) 1 expression in different inflammatory conditions $[8,22]$. In animal models, $\mathrm{OA}-\mathrm{NO}_{2}$ demonstrated a potential therapeutic effect in cardiac and renal ischemia and reperfusion via inhibiting the inflammatory mediator release and antioxidative stress [17, 23]. Nitrooleic acid attenuates colonic inflammation and improves the clinical symptoms in experimental inflammatory bowel disease [16]. In line with these observations, we previously revealed that the preventive treatment with $\mathrm{OA}-\mathrm{NO}_{2}$ depressed the systemic and local inflammatory responses and improved the multiorgan dysfunction in septic mice. The effective anti-inflammatory effect of $\mathrm{OA}-\mathrm{NO}_{2}$ appears to be attributable to the suppression of diverse proinflammatory mediators, including cytokines, 
chemokines, adhesion molecules, iNOS, and COX-2 [18]. In the present study, we established that the pretreatment with $\mathrm{OA}-\mathrm{NO}_{2}$ attenuated the cisplatin-induced kidney injury in mice through the inhibition of COX-2/mPGES-1/PGE 2 cascade expression and the suppressive action on other inflammatory cytokines.

The pathophysiological basis of cisplatin nephrotoxicity has been studied for the last three decades. However, only recently has the research been directed toward the understanding of its cellular and molecular mechanisms. Despite the intensive investigations, the processes underlying cisplatin nephrotoxicity are not fully understood. After administration, cisplatin is taken up in the renal tubular cells at high concentrations. The exposure of tubular cells to cisplatin activates complex signaling pathways that lead to the tubular cell injury and death. Meanwhile, robust inflammatory and oxidative stress responses are stimulated, further exacerbating the renal tissue damage. Cisplatin may also induce injury in the renal vasculature, leading to the ischemic tubular cell death and decreased glomerular filtration rate (GFR). These events accumulate and collectively culminate in the loss of renal functions during cisplatin nephrotoxicity, triggering acute renal failure. Among these multiple factors, inflammation plays the key role in the pathogenesis of cisplatin nephrotoxicity. It has been shown that cisplatin administration frequently results in the upregulation of proinflammatory mediators in the kidneys and activates the NF- $\kappa \mathrm{B}$ signaling pathway [24]. Among the inflammatory cytokines, the cyclooxygenase- (COX-) 2 has attracted more research attention and is considered to play an important role in mediating the cisplatin-induced renal injury [25].

Cyclooxygenase- (COX-) 2 is present throughout the different regions of the kidney and promotes the production of prostaglandins. It is involved in the constitutive production of prostanoids in the kidney and participates in the control of renal function and morphology. The most common action ascribed to COX-2 is the conversion of arachidonic acid to an intermediate endoperoxide that is converted to $\mathrm{PGE}_{2}$, PGI2, TXA2, or $\mathrm{PGD}_{2}$ through the actions of specific synthases [25]. Prostaglandin E2 $\left(\mathrm{PGE}_{2}\right)$, a major product of arachidonic acid metabolism, has an established role in mediating pain and inflammatory responses [26]. To date, three major forms of PGES have been cloned and characterized: the membrane-associated PGES- (mPGES-) 1, mPGES-2, and cytosolic PGES [27]. Similarly to COX-2, mPGES-1 is highly induced and expressed in macrophages in vitro $[28,29]$ and in the spleen and the lungs in vivo $[30,31]$ in response to proinflammatory stimuli. In addition to the findings mentioned above, COX-2 also plays an important role in mediating the cisplatin-induced renal injury. In our previous study [32], a three-day cisplatin treatment $(20 \mathrm{mg} / \mathrm{kg})$ induced a marked widespread upregulation of mPGES- 1 and COX-2 mRNA as well as of the protein levels and $\mathrm{PGE}_{2}$ content in the kidneys, while the renal expression of mPGES-2, cytosolic PGES, and COX-2 remained unaffected. However, the mPGES-1 KO mice were resistant to the cisplatin-induced renal dysfunction and structural damage, accompanied by suppressed inflammatory cytokine expression and oxidative stress. These results suggest that the activation of the COX-2/mPGES-1 pathway in the kidney may selectively mediate the cisplatininduced nephrotoxicity. Consistently with these findings, another study [33] demonstrated the increase in COX-2 mRNA and strong labeling of COX-2 protein in the renal interstitial cells after a five-day cisplatin $(13 \mathrm{mg} / \mathrm{kg})$ treatment in mice, whereas the concomitant application of the selective inhibitor of COX-2 ameliorated the cisplatin-induced mouse renal lesions through the inhibition of inflammatory and oxidative stress responses. On the other hand, COX-1 mRNA levels were not affected by cisplatin treatment, suggesting no participation of COX-1-induced prostaglandins in cisplatin nephrotoxicity.

In the present study, the cisplatin administration induced both the COX-2 and mPGES-1 mRNA and protein levels, along with the increased renal $\mathrm{PGE}_{2}$ content. The pretreatment with $\mathrm{OA}-\mathrm{NO}_{2}$ ameliorated the cisplatin-induced renal dysfunction and structural damage, accompanied by the suppressed expression of COX-2, mPGES-1, and other inflammatory cytokines. In spite of the already established anti-inflammatory effect of OA- $\mathrm{NO}_{2}$, we reported for the first time the capability of $\mathrm{OA}-\mathrm{NO}_{2}$ to directly suppress the COX-2 expression in the context of inflammation [18]. The present study further determined that the nitrofatty acid inhibited the COX-2/mPGES-1 expression in the condition of inflammation. Overall, the intervention of COX-2/mPGES$1 / \mathrm{PGE}_{2}$ pathway by $\mathrm{OA}-\mathrm{NO}_{2}$ in the cisplatin-treated mice may offer a novel approach for the management of the renal toxicity with added values of enhanced chemotherapeutic potential.

In addition to the COX-2/mPGES-1/PGE 2 pathway, the renal and circulator levels of TNF- $\alpha$, along with those of the renal interleukin-1 $\beta$ (IL-1 $\beta$ ), renal monocyte chemoattractant protein 1 (MCP-1), renal intercellular adhesion molecule1 (ICAM-1), and renal vascular cell adhesion molecule1 (VCAM-1), are upregulated by cisplatin administration [7]. Besides the intervention in the COX-2/mPGES-1/PGE 2 pathway, the pretreatment with $\mathrm{OA}-\mathrm{NO}_{2}$ also suppressed diverse proinflammatory mediators, including TNF- $\alpha$, IL$1 \beta$, MCP-1, ICAM-1, and VCAM-1. The beneficial effect of $\mathrm{OA}-\mathrm{NO}_{2}$ in the cisplatin nephrotoxicity animal model is partially attributed to the suppression of these inflammatory mediators. The results obtained are consistent with those of the previous study, which demonstrated that renal TNF- $\alpha$ and IL- $1 \beta$ mRNA expression in the cisplatin-treated WT mice increased but were almost completely blocked in the mPGES$1 \mathrm{KO}$ mice.

In summary, the present study evaluates in vivo the therapeutic effects of OA- $\mathrm{NO}_{2}$ in a mouse model of cisplatininduced nephrotoxicity. The preventative treatment with OA$\mathrm{NO}_{2}$ attenuated the cisplatin-induced renal dysfunction and structural damage. The beneficial effect of $\mathrm{OA}-\mathrm{NO}_{2}$ appears to be attributable to the intervention in the COX-2/mPGES$1 / \mathrm{PGE}_{2}$ pathway and the suppression of proinflammatory mediators, including TNF- $\alpha$, IL- $1 \beta$, MCP-1, ICAM-1, and VCAM-1. Taken together, nitroalkenes may hold promise for prevention and possibly therapy of cisplatin-induced kidney injury. 


\section{Conflict of Interests}

The authors declare that there is no conflict of interests regarding the publication of this paper.

\section{Acknowledgment}

This work was supported by the National Natural Science Foundation of China (Grant no. 81200530) (to Haiping Wang).

\section{References}

[1] G. Giaccone, "Clinical perspectives on platinum resistance," Drugs, vol. 59, supplement 4, pp. 9-17, 37-38, 2000.

[2] J. T. Hartmann and H.-P. Lipp, "Toxicity of platinum compounds," Expert Opinion on Pharmacotherapy, vol. 4, no. 6, pp. 889-901, 2003.

[3] D. R. Luke, K. Vadiei, and G. Lopez-Berestein, "Role of vascular congestion in cisplatin-induced acute renal failure in the rat," Nephrology Dialysis Transplantation, vol. 7, no. 1, pp. 1-7, 1992.

[4] T. L. Cornelison and E. Reed, "Nephrotoxicity and hydration management for cisplatin, carboplatin, and ormaplatin," Gynecologic Oncology, vol. 50, no. 2, pp. 147-158, 1993.

[5] K. B. Meyer and N. E. Madias, "Cisplatin nephrotoxicity," Mineral and Electrolyte Metabolism, vol. 20, no. 4, pp. 201-213, 1994.

[6] N. Pabla and Z. Dong, "Cisplatin nephrotoxicity: mechanisms and renoprotective strategies," Kidney International, vol. 73, no. 9, pp. 994-1007, 2008.

[7] G. Ramesh and W. Brian Reeves, "TNF- $\alpha$ mediates chemokine and cytokine expression and renal injury in cisplatin nephrotoxicity," Journal of Clinical Investigation, vol. 110, no. 6, pp. 835$842,2002$.

[8] T. Cui, F. J. Schopfer, J. Zhang et al., "Nitrated fatty acids: endogenous anti-inflammatory signaling mediators," The Journal of Biological Chemistry, vol. 281, no. 47, pp. 35686-35698, 2006.

[9] P. N. Cunningham, H. M. Dyanov, P. Park, J. Wang, K. A. Newell, and R. J. Quigg, "Acute renal failure in endotoxemia is caused by TNF acting directly on TNF receptor-1 in kidney," The Journal of Immunology, vol. 168, no. 11, pp. 5817-5823, 2002.

[10] P. R. S. Baker, Y. Lin, F. J. Schopfer et al., "Fatty acid transduction of nitric oxide signaling: multiple nitrated unsaturated fatty acid derivatives exist in human blood and urine and serve as endogenous peroxisome proliferator-activated receptor ligands," Journal of Biological Chemistry, vol. 280, no. 51, pp. 42464-42475, 2005.

[11] J. Zhang, L. Villacorta, L. Chang et al., "Nitro-oleic acid inhibits angiotensin II-induced hypertension," Circulation Research, vol. 107, no. 4, pp. 540-548, 2010.

[12] M. P. Cole, T. K. Rudolph, N. K. H. Khoo et al., "Nitro-fatty acid inhibition of neointima formation after endoluminal vessel injury," Circulation Research, vol. 105, no. 10, pp. 965-972, 2009.

[13] H. Wang, H. Liu, Z. Jia, G. Guan, and T. Yang, "Effects of endogenous PPAR agonist nitro-oleic acid on metabolic syndrome in obese Zucker rats," PPAR Research, vol. 2010, Article ID 601562, 7 pages, 2010.

[14] F. J. Schopfer, M. P. Cole, A. L. Groeger et al., "Covalent peroxisome proliferator-activated receptor $\gamma$ adduction by nitrofatty acids: selective ligand activity and anti-diabetic signaling actions," The Journal of Biological Chemistry, vol. 285, no. 16, pp. 12321-12333, 2010.

[15] L. Villacorta, L. Chang, S. R. Salvatore et al., "Electrophilic nitro-fatty acids inhibit vascular inflammation by disrupting LPS-dependent TLR4 signalling in lipid rafts," Cardiovascular Research, vol. 98, no. 1, pp. 116-124, 2013.

[16] S. Borniquel, E. A. Jansson, M. P. Cole, B. A. Freeman, and J. O. Lundberg, "Nitrated oleic acid up-regulates PPAR $\gamma$ and attenuates experimental inflammatory bowel disease," Free Radical Biology and Medicine, vol. 48, no. 4, pp. 499-505, 2010.

[17] H. Liu, Z. Jia, S. Soodvilai et al., "Nitro-oleic acid protects the mouse kidney from ischemia and reperfusion injury," The American Journal of Physiology - Renal Physiology, vol. 295, no. 4, pp. F942-F949, 2008.

[18] H. Wang, H. Liu, Z. Jia et al., "Nitro-oleic acid protects against endotoxin-induced endotoxemia and multiorgan injury in mice," The American Journal of Physiology - Renal Physiology, vol. 298, no. 3, pp. F754-F762, 2010.

[19] M. S. Rangel-Frausto, D. Pittet, M. Costigan, T. Hwang, C. S. Davis, and R. P. Wenzel, "The natural history of the systemic inflammatory response syndrome (SIRS): a prospective study," The Journal of the American Medical Association, vol. 273, no. 2, pp. 117-123, 1995.

[20] D. Levy, A. Höke, and D. W. Zochodne, "Local expression of inducible nitric oxide synthase in an animal model of neuropathic pain," Neuroscience Letters, vol. 260, no. 3, pp. 207209, 1999.

[21] S. Naureckiene, W. Edris, S. K. Ajit et al., "Use of a murine cell line for identification of human nitric oxide synthase inhibitors," Journal of Pharmacological and Toxicological Methods, vol. 55, no. 3, pp. 303-313, 2007.

[22] F. J. Schopfer, Y. Lin, P. R. S. Baker et al., "Nitrolinoleic acid: an endogenous peroxisome proliferator-activated receptor $\gamma$ ligand," Proceedings of the National Academy of Sciences of the United States of America, vol. 102, no. 7, pp. 2340-2345, 2005.

[23] V. Rudolph, T. K. Rudolph, F. J. Schopfer et al., "Endogenous generation and protective effects of nitro-fatty acids in a murine model of focal cardiac ischaemia and reperfusion," Cardiovascular Research, vol. 85, no. 1, pp. 155-166, 2010.

[24] J. Deng, Y. Kohda, H. Chiao et al., "Interleukin-10 inhibits ischemic and cisplatin-induced acute renal injury," Kidney International, vol. 60, no. 6, pp. 2118-2128, 2001.

[25] K. N. M. Khan, C. M. Venturini, R. T. Bunch et al., "Interspecies differences in renal localization of cyclooxygenase isoforms: implications in nonsteroidal antiinflammatory drug-related nephrotoxicity," Toxicologic Pathology, vol. 26, no. 5, pp. 612620, 1998.

[26] M. D. Breyer and R. M. Breyer, "G protein-coupled prostanoid receptors and the kidney," Annual Review of Physiology, vol. 63, pp. 579-605, 2001.

[27] M. Murakami and I. Kudo, "Prostaglandin E synthase: a novel drug target for inflammation and cancer," Current Pharmaceutical Design, vol. 12, no. 8, pp. 943-954, 2006.

[28] C. E. Trebino, J. L. Stock, C. P. Gibbons et al., "Impaired inflammatory and pain responses in mice lacking an inducible prostaglandin E synthase," Proceedings of the National Academy of Sciences of the United States of America, vol. 100, no. 15, pp. 9044-9049, 2003.

[29] S. Uematsu, M. Matsumoto, K. Takeda, and S. Akira, "Lipopolysaccharide-dependent prostaglandin E(2) production is regulated by the glutathione-dependent prostaglandin $\mathrm{E}(2)$ 
synthase gene induced by the toll-like receptor 4/MyD88/NFIL6 pathway," Journal of Immunology, vol. 168, no. 11, pp. 5811-5816, 2002.

[30] L. Boulet, M. Ouellet, K. P. Bateman et al., "Deletion of microsomal prostaglandin $\mathrm{E}_{2}\left(\mathrm{PGE}_{2}\right)$ synthase-1 reduces inducible and basal $\mathrm{PGE}_{2}$ production and alters the gastric prostanoid profile," The Journal of Biological Chemistry, vol. 279, no. 22, pp. 2322923237, 2004.

[31] M. Murakami, K. Nakashima, D. Kamei et al., "Cellular prostaglandin E2 production by membrane-bound prostaglandin E synthase-2 via both cyclooxygenases-1 and -2," Journal of Biological Chemistry, vol. 278, no. 39, pp. 37937-37947, 2003.

[32] Z. Jia, N. Wang, T. Aoyagi, H. Wang, H. Liu, and T. Yang, "Amelioration of cisplatin nephrotoxicity by genetic or pharmacologic blockade of prostaglandin synthesis," Kidney International, vol. 79, no. 1, pp. 77-88, 2011.

[33] S. Honma, N. Takahashi, M. Shinohara et al., "Amelioration of cisplatin-induced mouse renal lesions by a cyclooxygenase (COX)-2 selective inhibitor," European Journal of Pharmacology, vol. 715, no. 1-3, pp. 181-188, 2013. 


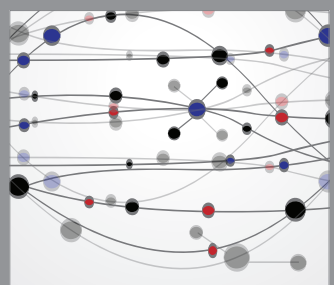

The Scientific World Journal
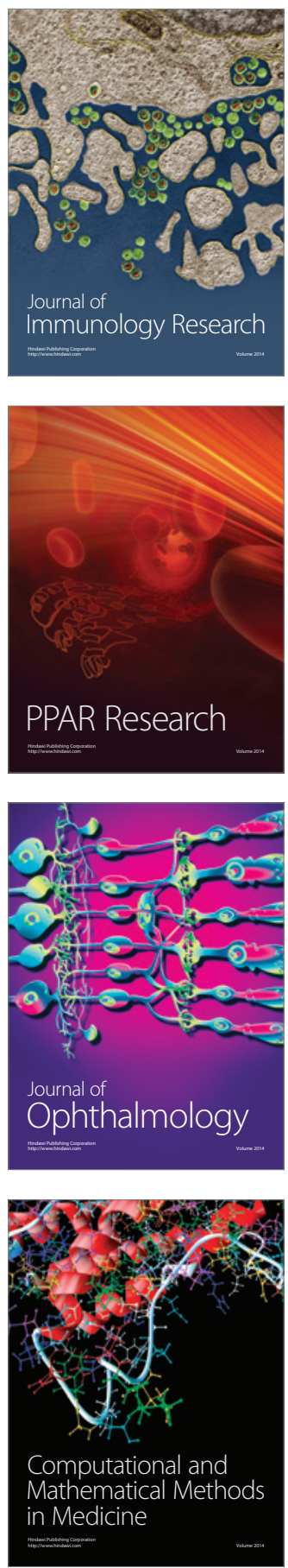

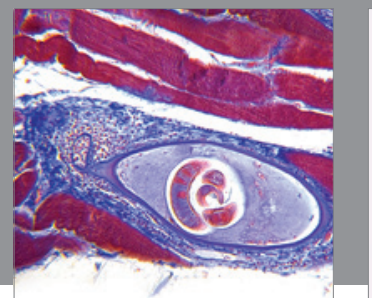

Gastroenterology

Research and Practice
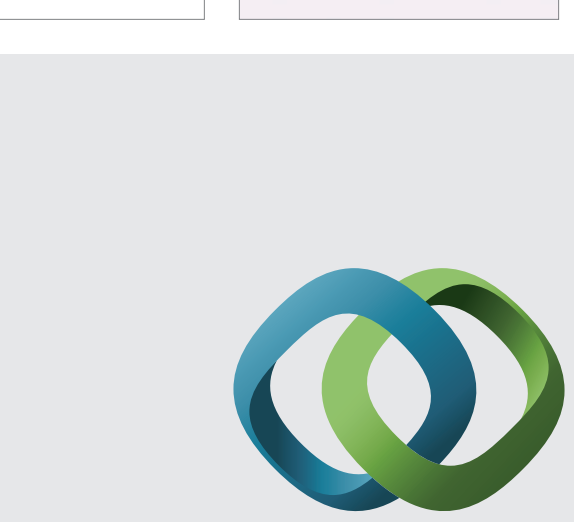

\section{Hindawi}

Submit your manuscripts at

http://www.hindawi.com
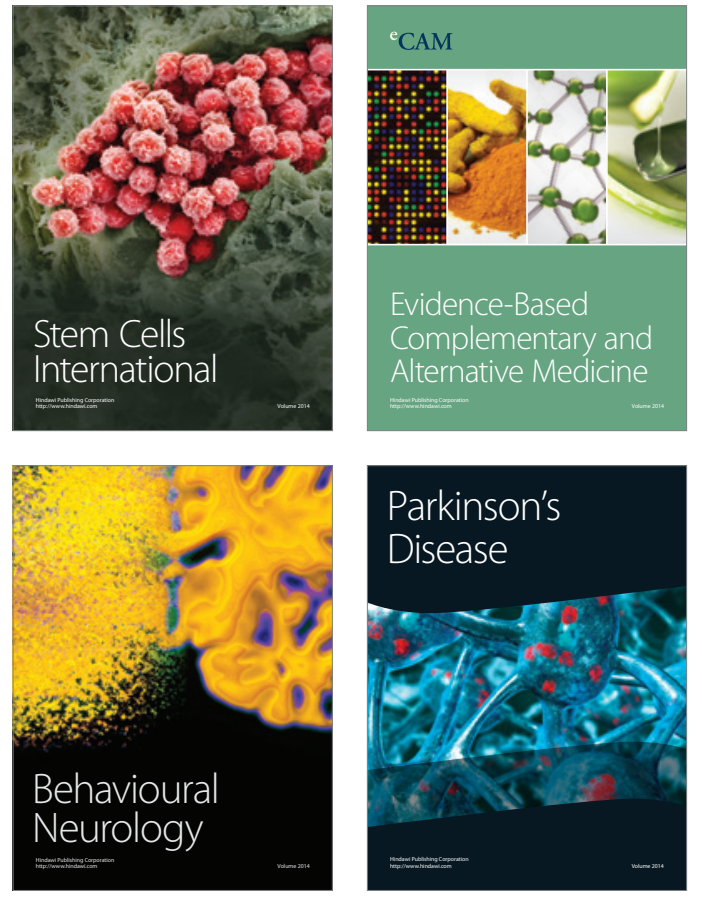
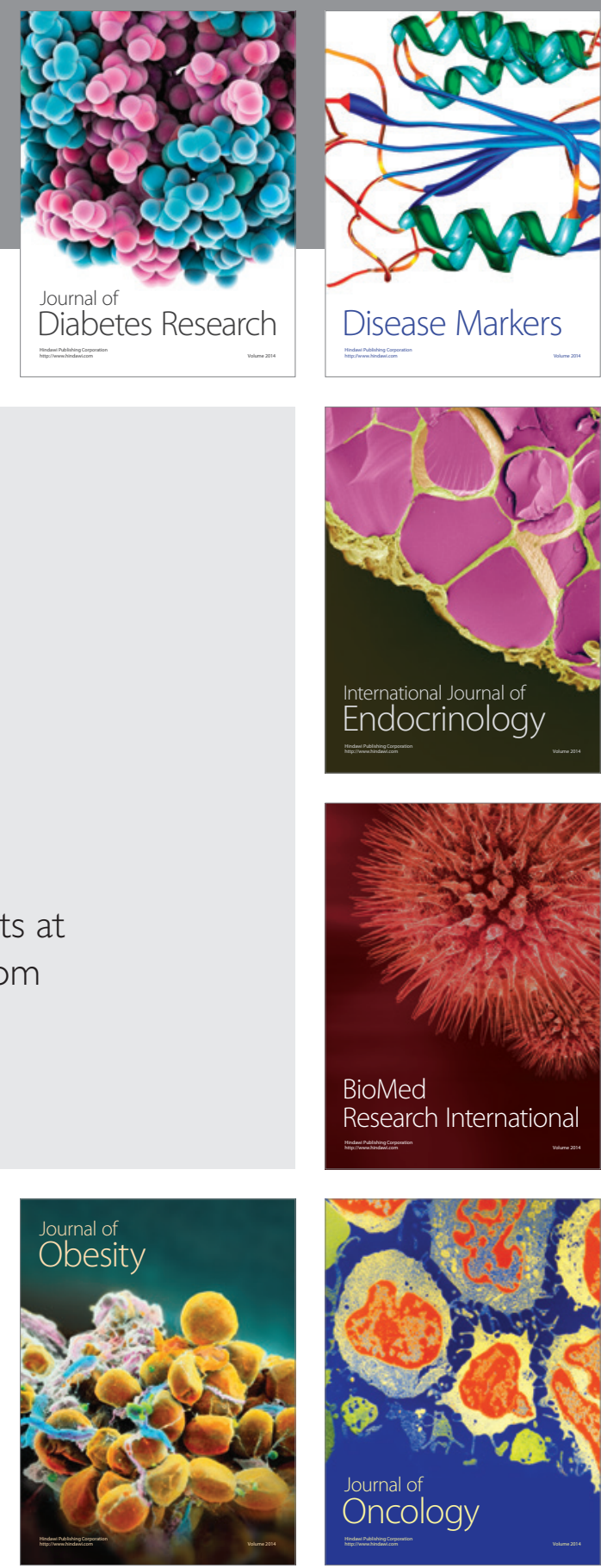

Disease Markers
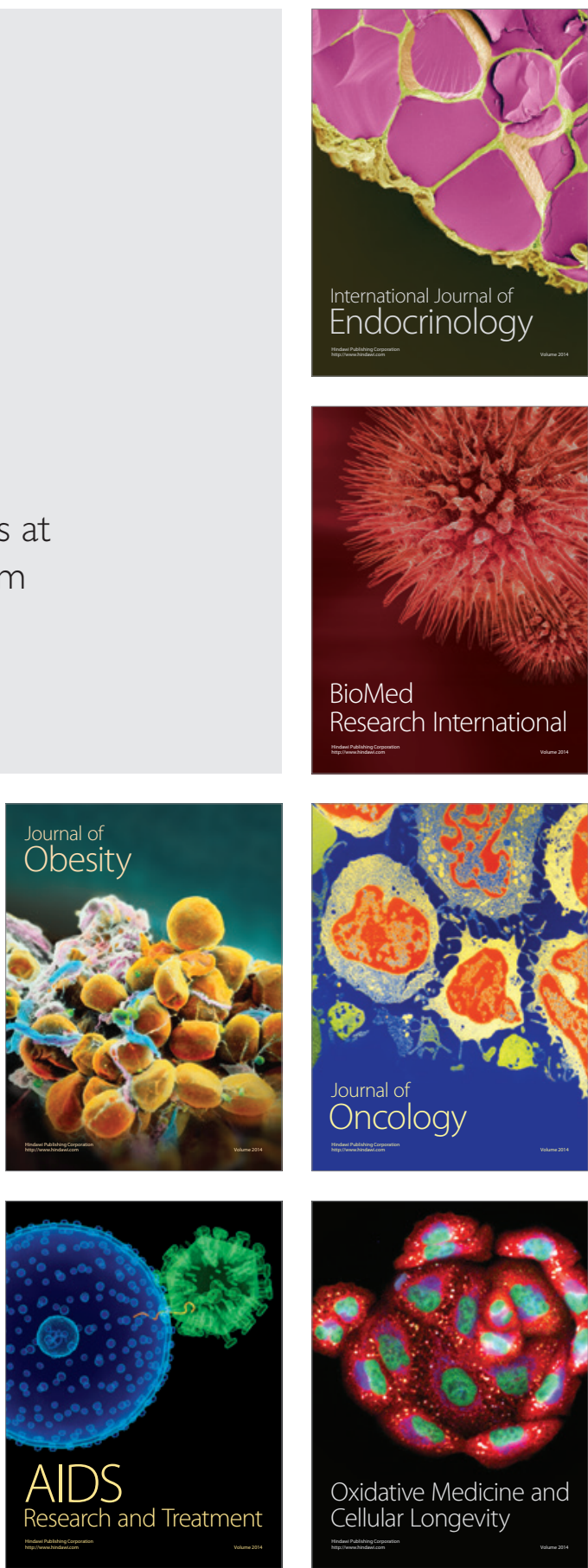